Portland State University

PDXScholar

Environmental Science and Management

Faculty Publications and Presentations

$7-2018$

\title{
Water Flow and Biofilm Cover Influence Environmental DNA Detection in Recirculating Streams
}

Arial Shogren

University of Notre Dame

Jennifer L. Tank

University of Notre Dame

Scott P. Egan

Rice University

Olivia August

University of Notre Dame

Emma J. Rosi

Cary Institute of Ecosystem Studies

Follow this and additional works at: https://pdxscholar.library.pdx.edu/esm_fac

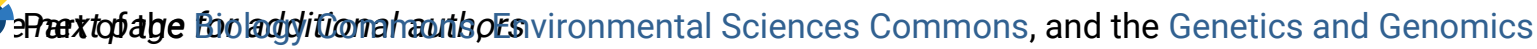
Commons

Let us know how access to this document benefits you.

\section{Citation Details}

Shogren, A. J., Tank, J. L., Egan, S. P., August, O., Rosi, E. J., Hanrahan, B. R., ... \& Bolster, D. (2018). Water Flow and Biofilm Cover Influence Environmental DNA Detection in Recirculating Streams. Environmental science \& technology, 52(15), 8530-8537.

This Post-Print is brought to you for free and open access. It has been accepted for inclusion in Environmental Science and Management Faculty Publications and Presentations by an authorized administrator of PDXScholar. Please contact us if we can make this document more accessible: pdxscholar@pdx.edu. 


\section{Authors}

Arial Shogren, Jennifer L. Tank, Scott P. Egan, Olivia August, Emma J. Rosi, Brittany R. Hanrahan, Mark A. Renshaw, Crysta A. Gantz, and Diogo Bolster 
Subscriber access provided by MICHIGAN STATE UNIVERSITY | MSU LIBRARIES

Environmental Measurements Methods

\section{Water flow and biofilm cover influence environmental DNA (eDNA) detection in recirculating streams}

Arial Shogren, Jennifer L. Tank, Scott Patrick Egan, Olivia August, Emma J

Rosi, Brittany R Hanrahan, Mark A Renshaw, Crysta A Gantz, and Diogo Bolster

Environ. Sci. Technol., Just Accepted Manuscript • DOI: 10.1021/acs.est.8b01822 • Publication Date (Web): 11 Jul 2018

Downloaded from http://pubs.acs.org on July 17, 2018

\section{Just Accepted}

"Just Accepted" manuscripts have been peer-reviewed and accepted for publication. They are posted online prior to technical editing, formatting for publication and author proofing. The American Chemical Society provides "Just Accepted" as a service to the research community to expedite the dissemination of scientific material as soon as possible after acceptance. "Just Accepted" manuscripts appear in full in PDF format accompanied by an HTML abstract. "Just Accepted" manuscripts have been fully peer reviewed, but should not be considered the official version of record. They are citable by the Digital Object Identifier (DOI®). "Just Accepted" is an optional service offered to authors. Therefore, the "Just Accepted" Web site may not include all articles that will be published in the journal. After a manuscript is technically edited and formatted, it will be removed from the "Just Accepted" Web site and published as an ASAP article. Note that technical editing may introduce minor changes to the manuscript text and/or graphics which could affect content, and all legal disclaimers and ethical guidelines that apply to the journal pertain. ACS cannot be held responsible for errors or consequences arising from the use of information contained in these "Just Accepted" manuscripts. 
1 Title: Water flow and biofilm cover influence environmental DNA (eDNA) detection in recirculating streams

Author List: Arial J. Shogren ${ }^{1,}{ }^{*}$, Jennifer L. Tank ${ }^{1}$, Scott P. Egan ${ }^{3}$, Olivia August ${ }^{1}$, Emma J. Rosi $^{4}$, Brittany R. Hanrahan ${ }^{1}$, Mark A. Renshaw ${ }^{1,5}$, Crysta A. Gantz ${ }^{1,6}$, Diogo Bolster ${ }^{2}$

Author Affiliations:

${ }^{1}$ University of Notre Dame, Department of Biological Sciences, Environmental Change Initiative, Notre Dame, Indiana, USA

${ }^{2}$ University of Notre Dame, Department of Civil and Environmental Engineering and Earth Sciences, Notre Dame, Indiana, USA

${ }^{3}$ Rice University, Biosciences Department, Houston, Texas, USA

${ }^{4}$ Cary Institute of Ecosystem Studies, Millbrook, New York, USA

* A.J. Shogren is the corresponding author

\footnotetext{
${ }^{5}$ M.A. Renshaw - Oceanic Institute of Hawaii Pacific University, Shrimp Department, Hawaii, USA (mrenshaw@hpu.edu)

${ }^{6}$ C.A. Gantz - Portland State University, Portland, Oregon, USA (cgantz@pdx.edu)
} 
Abstract:

The increasing use of environmental DNA (eDNA) for determination of species presence

26 in aquatic ecosystems is an invaluable technique for both the ecology as a field and for the

27 management of aquatic ecosystems. We examined the degradation dynamics of fish eDNA using

28 an experimental array of recirculating streams using a "nested" primer assay to estimate

29 degradation among eDNA fragment sizes. We introduced eDNA into streams with a range of

30 water velocities $\left(0.1-0.8 \mathrm{~m} \mathrm{~s}^{-1}\right)$ and substrate biofilm coverage (0-100\%), and monitored eDNA

31 concentrations over time $(\sim 10 \mathrm{~d})$ to assess how biophysical conditions influence eDNA

32 persistence. We found that the presence of biofilm significantly increased initial decay rates

33 relative to previous studies conducted in non-flowing microcosms, suggesting important

34 differences in detection and persistence in lentic vs. lotic systems. Lastly, by using a nested

35 primer assay that targeted different size eDNA fragments, we found that fragment size altered

36 both the estimated rate constant coefficients, as well as eDNA detectability over time. Larger

37 fragments (>600bp) were quickly degraded, while shorter fragments $(<100 \mathrm{bp})$ remained

38 detectable for the entirety of the experiment. When using eDNA as a stream monitoring tool,

39 understanding environmental factors controlling eDNA degradation will be critical for improving 40 eDNA sampling strategies.

41

42 Key Words: eDNA, degradation, nested primer assay 

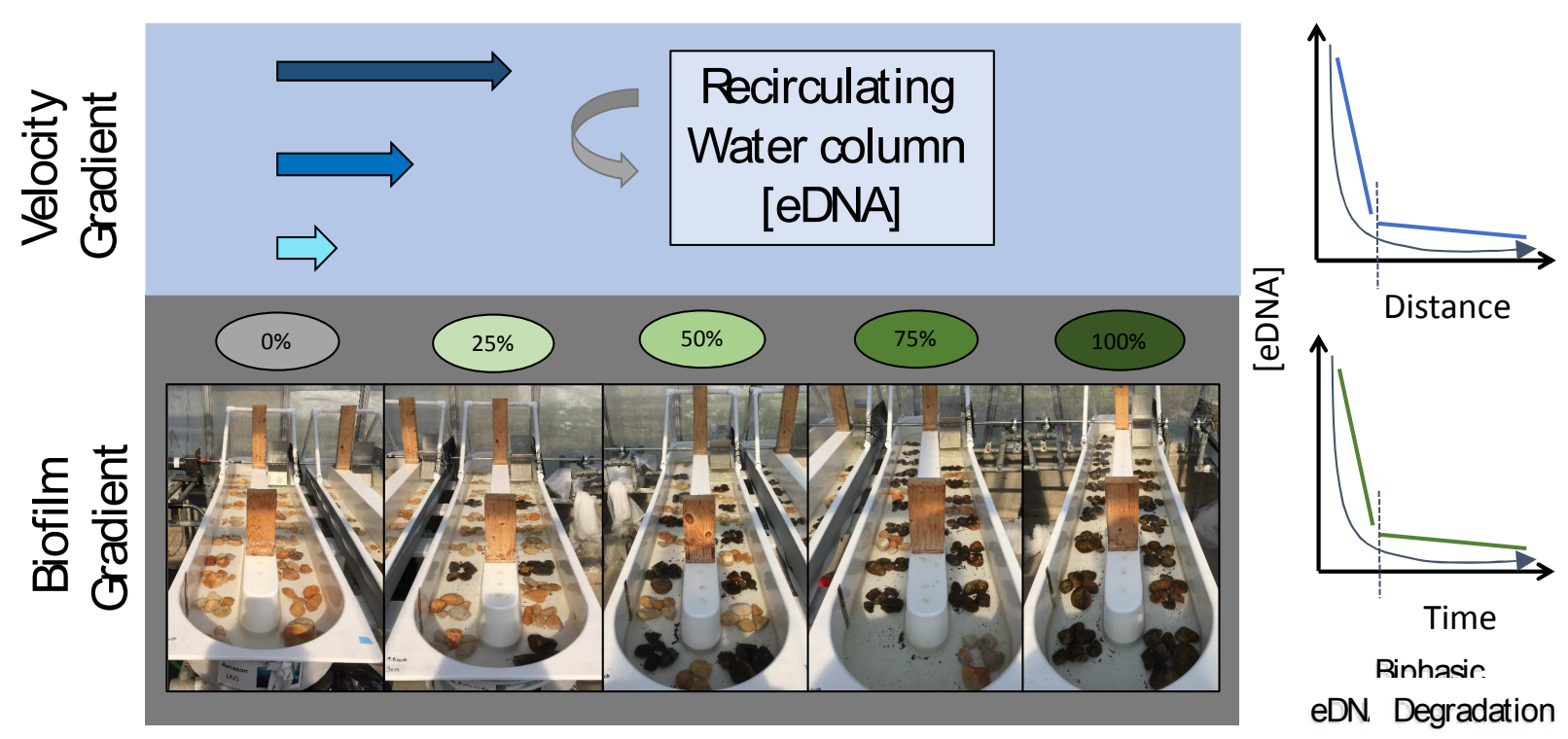

\section{Introduction:}

Modern conservation science and natural resource management are in an era of rapid

50 transformation, facilitated by a growing molecular "toolbox" of approaches that enable the

51 identification of targeted species in environmental samples without direct observation ${ }^{1-3}$. The

52 emergence of modern molecular techniques for inference of species presence in ecology has

53 been bolstered by the development and application of environmental DNA (hereafter, eDNA)

54 methods for many species in aquatic systems ${ }^{4}$. The eDNA approach uses genetic material

55 captured and identified from water samples, and can include free-floating extracellular DNA,

56 feces, tissue, and other excretions and sloughed materials ${ }^{2,4,5}$. The rapidly expanding use of

57 eDNA techniques towards direct applications, including species monitoring and management, is

58 directly related to the higher sensitivity of the approach relative to conventional sampling

59 methods such as netting, seining, and snorkel surveys ${ }^{6}$. Despite the growing use of eDNA for 
60 invasive, rare, and endangered species monitoring applications ${ }^{7-11}$, methodological testing is still

61 required to determine the inferences that can be drawn from eDNA detection in varying aquatic

62 systems. This may include the standardization of eDNA sampling strategies and sampling design

$63^{12}$, in addition to recognition of what environmental factors influence detectability in space and

64 time.

65 Importantly, optimizing eDNA techniques in flowing aquatic systems has significant 66 potential to move the technique towards applications beyond presence/absence information ${ }^{13}$,

67 which is the ultimate goal for both monitoring rare species and for the management of invasive

68 species ${ }^{14,15}$. First, these applications must be sensitive enough to detect species reliably when

69 they are rare or in low abundance, which can result in false negatives ${ }^{16,17}$. Second, these

70 methods need to account for flow and environmental conditions, as eDNA signals become

71 diluted as they are transported downstream and the probability of positive detection decreases ${ }^{18}$.

72 Additionally, determining the precise source of eDNA in flowing systems is challenging due to

73 the combined effect of downstream transport ${ }^{18}$ and eDNA degradation ${ }^{5,19-23}$, which alter eDNA

74 concentration in the water column after it is released from an organism ${ }^{24-26}$. Moreover, rapid

75 degradation has been hypothesized as a cause of decreased detectability over time, and therefore

76 limits temporal and spatial inference of positive detections; the result is an increased potential for

77 false negative detection when a species is present ${ }^{20}$.

78 In addition to the challenges resulting from transport, there is a stark lack of data that

79 may show how biological factors, such as substrate biofilm colonization, can influence eDNA

80 rate constants in flowing waters. To date, a majority of eDNA degradation studies have been

81 performed in non-flowing mesocosms or standing water such as ponds ${ }^{5,19,27}$. While variation in

82 the biology of the water column has been shown to influence rate constants ${ }^{19}$, there have been 
83 no previous studies investigating the influence of benthic biofilms on eDNA degradation in

84 flowing waters. Importantly, the presence of biofilms strongly influences the retention of

85 nutrients, carbon, and particles during downstream transport ${ }^{28-32}$, and the inherent properties and

86 physical structure of biofilms can entrap eDNA and may promote in situ decay ${ }^{30}$.

87 In this study, we assess the impact of biological (i.e., biofilm) and physical (i.e., water

88 flow) stream characteristics, and their interactions, on the degradation rate coefficients of eDNA.

89 We set up artificial recirculating streams with varying biofilm coverage, introducing known

90 quantities of fish eDNA into recirculating artificial streams to measure the decline in eDNA

91 concentration over time. Our goal was to address two key questions: 1) Does water velocity,

92 which ranges considerably in natural streams, influence eDNA rate constants? and 2) How does

93 the presence of benthic biofilms alter eDNA rate constants? We hypothesized that lower flow

94 velocities would increase eDNA removal from the water column due to the increased potential

95 for settling, while conversely, higher velocities would promote either continued suspension or

96 resuspension of eDNA particles during recirculation. While these measures might not influence

97 the true rate of eDNA decay, they would be included in the overall removal of eDNA from

98 detection and would thus influence how far downstream eDNA might potentially travel. We

99 expected that increased biofilm coverage would also increase eDNA removal rates, due to

100 increased retention and processing. In most studies to date, only uncolonized substrate has been

101 considered, but it is known that streambed surfaces, and their associated biophysical complexity,

102 can significantly impact retention of eDNA ${ }^{18,30}$. Additionally, we expected that rate constant

103 would depend strongly on eDNA fragment length, and thus we applied a "nested primer"

104 approach ${ }^{33,34}$ to assess rate constants of varying fragment length in recirculatinsg streams. While

105 such an approach has been used for estimating fish biomass ${ }^{34}$ and for assessing eDNA 
106 degradation in water tanks ${ }^{33}$, we empirically tested the utility of fragment length as a result of

107 primer choice under the presence of flow and varying biofilm coverage.

108

109 Methods

110 Site Description

111 We conducted a 10-day experiment in August 2015 using 15 artificial streams

112 constructed of composite fiberglass, which were housed in a greenhouse at the Cary Institute of

113 Ecosystem Studies, Millbrook, NY. Because we wanted to isolate the influence of substrate

114 biofilm and velocity, we kept all physiochemical factors such as water $\mathrm{pH}$, temperature, and

115 nutrient concentrations consistent among streams. We allocated the artificial streams along two

116 experimental gradients: velocity $\left(\right.$ Low $=0.1 \mathrm{~m} \mathrm{~s}^{-1}$, Intermediate $=0.5 \mathrm{~m} \mathrm{~s}^{-1}$, High $\left.=0.85 \mathrm{~m} \mathrm{~s}^{-1}\right)$

117 and the proportion of rocks colonized with biofilm, relative to uncolonized rocks, at 5 levels $(0$,

$11825,50,75,100 \%)$. For the biofilm treatment, three months prior to our experiment, we deployed

119 rocks (cobbles, 5-10 cm diameter quartz Maryland River Rock; Ayers Supply, Clarks Summit,

120 PA) in a riffle-run section of a nearby $4^{\text {th }}$ order woodland stream (East Branch, Wappinger's

121 Creek, NY). After the three-month incubation period, rocks had well-developed biofilm. To

122 establish our biofilm treatment in the artificial streams, we transported colonized rocks to the

123 artificial stream facility in large buckets with a small amount of stream water. We then placed 0 ,

$12425,50,75$, or 100 colonized rocks into each stream, adding the appropriate number of bare rocks

125 to ensure that each stream contained 100 total rocks. We placed all rocks in the streams in

126 clusters, with biofilm-colonized surface up to mimic natural stream-bottom conditions. Using

127 rocks taken from the streams within the first $24 \mathrm{hrs,}$, we quantified biofilm (as chlorophyll a and

128 organic matter) using standard methods (see SI Figure 2). For the velocity treatment, one 
129 paddlewheel motor rotated for a block of 5 streams, keeping recirculating velocity constant in

130 that block of streams. We manually set the motors and then used a tachometer to measure the

131 rotations per minute (rpm), converting rpm to water velocity using the angular flow of the paddle

132 wheel $\left(\mathrm{rpm} * 2 \pi \mathrm{r} / 60 \mathrm{~s}=\mathrm{m} \mathrm{s}^{-1}\right)$. After substrate placement and tuning the paddle wheels, we

133 filled each stream with $20 \mathrm{~L}$ of low-nutrient groundwater and allowed biofilms to acclimate in

134 the artificial streams for one day prior to eDNA addition.

136 Experimental addition of rainbow trout eDNA

137 To determine that the streams did not contain any target eDNA, we sampled the water

138 column for eDNA in each stream after adding biofilm-colonized rocks and prior to adding our

139 eDNA solution, and we found no detectable target eDNA in any pre-experiment water samples.

140 Once the streams had acclimated for $24 \mathrm{hrs}$, we added $20 \mathrm{~L}$ of water with rainbow trout $(O$.

141 mykiss) eDNA to each stream for a total experimental volume of $40 \mathrm{~L}$. We collected our eDNA

142 "release" water from a hatchery pool filled with rainbow trout fry at the New York Department

143 of Environmental Conservation Fish Hatchery in Van Hornesville (NY) and used the solutions

144 within 3 hours of collection. Before addition to the recirculating streams, we filtered the release

145 water through $1 \mathrm{~mm}$ mesh to remove any large particles. Prior to addition, we obtained our

146 starting eDNA concentration by sampling the eDNA solution $(\mathrm{N}=15)$ using $250 \mathrm{~mL}$ bottles,

147 which were immediately filtered and stored (see SI methods).

148 After adding the rainbow trout eDNA release solution, we collected $250 \mathrm{~mL}$ samples

149 from each stream over the course of 10 days, at intervals of $15 \mathrm{~min}, 30 \mathrm{~min}, 1,1.5,2,4,8,12,18$

$150 \mathrm{hr}$, and $1,1.5$, and 2 days, and then daily for the next 10 days ( $\mathrm{n}=20$ sampling points per stream).

151 Each time we collected a sample, we replaced the sample volume with $250 \mathrm{~mL}$ of groundwater, 
152 and we also replaced the water lost due to daily evaporation using the same low-nutrient

153 groundwater $(\sim 1-5 \mathrm{~L})$, to maintain all streams at the same flow volume throughout the

154 experiment. We replaced any lost water (from evaporation or sampling) using low-nutrient

155 groundwater from the stream facility. After sampling, we briefly stored each eDNA sample on

156 ice in coolers before filtering; each sample was filtered within 30 minutes of collection. We

157 tested for eDNA contamination in two ways: we placed five sealed $250 \mathrm{~mL}$ sample bottles filled

158 with DI water into the storage coolers and in the lab, we filtered five samples of $250 \mathrm{~mL}$ of

159 groundwater from the Artificial Stream Facility. We then processed the cooler and lab blanks in

160 the same manner as stream samples. Detailed protocols for sample filtration and storage, eDNA

161 extraction and quantification, and primer set development can be found in the SI Methods and SI

162 Table 1.

163

164 Modeling and Statistical Analysis:

165 First, in order to confirm the implementation of our biofilm treatments, we used one-way

166 ANOVAs to test for differences among biofilm biomass metrics (i.e., chl $a$ and benthic OM), in

167 addition to temperature, dissolved organic carbon, and $\mathrm{pH}$ (SI Figure 1).

168 Then, we measured the eDNA concentration from each sample using three different

169 primers that amplify different fragment lengths (697, 347, and $97 \mathrm{bp})$ along the same gene,

170 removing data with concentrations below the qPCR limit of quantification determined by our

171 standard (5 copies $/ \mathrm{mL})$. Using all data that was above our limit of quantification, we analyzed

172 the change in eDNA concentration data over the temporal sampling sequence using two fitting

173 procedures to determine the best representation of eDNA decay: a single-phase exponential

174 degradation model or a biphasic (two-phase) degradation model. Biphasic degradation indicates 
175 that a portion of material is biologically labile or physically "sticky" and thus removed from

176 detection quickly in the first phase of degradation. The remaining portion is more resistant to

177 degradation ${ }^{35}$, and is either more recalcitrant or less likely to become physically trapped in the

178 benthos. To estimate these two rate constants, we confirmed these breakpoints statistically using

179 the package segmented ${ }^{36,37}$ in R (Version 3.5.0), which optimizes the highest coefficient of

180 determination of each trend line $\left(\mathrm{R}^{2}\right)$. Then we fit a line to the first section of data (on a log-

181 linear graph) until break point, $\mathrm{t}^{\prime}$. The slope of the first line corresponds to $\mathrm{k}_{1}\left(\mathrm{day}^{-1}\right)$, or the

182 primary rate constant, while the fit of the line after the breakpoint represents $\mathrm{k}_{2}\left(\mathrm{day}^{-1}\right)$, the

183 secondary rate constant. These two parameters were combined to create a continuous fit equation

$184{ }^{19}$ where $\mathrm{C}_{0}$ is the initial concentration:

$$
C=C(i)\left\{\begin{array}{c}
C_{o} e^{-k_{1} t} \text { if } t<t^{\prime} \\
C_{o} e^{-k_{1} t^{\prime}} e^{-k_{2}\left(t-t^{\prime}\right)} \text { if } t \geq t^{\prime}
\end{array}\right.
$$

185 In some cases, only a single-phase model was necessary as no breakpoint was observed, and the

186 data was fit to a single-phase exponential degradation model: $\mathrm{C}=\mathrm{C}_{0} \mathrm{e}^{-\mathrm{kt}}$. We also tested for the

187 effect of chlorophyll a and biofilm organic matter on each term $\left(\mathrm{k}_{1}, \mathrm{k}_{2}\right.$, and $\left.\mathrm{t}^{\prime}\right)$ using stepwise

188 linear regression analyses.

189 Then, to compare eDNA degradation between each stream, we also used a linear mixed

190 effects model (abbreviated as LMM) to evaluate the differences in estimated rate constant

191 coefficients among primer lengths and across the factorial treatments using R package $L M E 4^{38}$.

192 The model included both random effect on each stream and fixed effects on the velocity and

193 biofilm treatment, as well as the model intercept. We also tested for interactions, such as bio*vel,

194 bio*time, and vel*bio. Summary statistics can be found in SI Table 3.

195 Finally, in addition to estimating each parameter, we used a select subset of scenarios to

196 compare both experimental treatments (biofilm x flow) and the influence of primer size (i.e., 
$197 C(i)=C_{o} e^{-k_{1} t}$ ) using the $\mathrm{k}_{1}$ term for the primer amplifying 97 and $697 \mathrm{bp}$ fragments for the

198 four velocity/biofilm treatments from the artificial streams (Low $-0 \%$ biofilm, Low $-100 \%$

199 biofilm, High - 0\% biofilm, High - 100\% biofilm). For each, we modeled the decline in eDNA

200 concentration from 100,000 eDNA copies $\mathrm{mL}^{-1}$, estimating eDNA concentration, based on the

201 predictive model, at times $1,3,6,8,12$, and $24 \mathrm{hrs}$ from the initial release. This starting

202 concentration is high and represents quantities that would come out of a fish hatchery or a

203 densely populated area. To extend our results to what would happen in flowing waters, we also

204 converted the eDNA decay over time to decay over distance using the equation $\mathrm{C}=\mathrm{C}_{0} \mathrm{e}^{-\mathrm{kx}}$, where

$205 \mathrm{x}$ is distance downstream in meters, for both the low and high velocity treatments $\left(0.1 \mathrm{~m} \mathrm{~s}^{-1}\right.$ and

$\left.2060.8 \mathrm{~m} \mathrm{~s}^{-1}\right)$.

207 We performed all modeling and statistical analyses using R Studio (R Version 3.5.0), and 208 summary statistics can be found in SI Table 3.

$210 \underline{\text { Results \& Discussion }}$

211 Biphasic degradation is an important "fate" of eDNA

212 The successful detection of eDNA in the water column is the combined result of

213 production, removal mechanisms, and degradation, and these factors contribute to the sporadic

214 distribution of eDNA in the aquatic environments ${ }^{20}$. Previous studies, such as work by

215 Eichmiller et al. ${ }^{19}$ and others ${ }^{39}$, suggests that some proportion of aquatic eDNA is likely labile

216 and degrades quickly, while the remainder is more resistant to degradation. Our findings are

217 consistent with these earlier studies as a biphasic exponential degradation model consistently

218 produced a better fit to the eDNA degradation data in all streams and for all fragment lengths $\left(\mathrm{R}^{2}\right.$

$219=0.72-0.99 ;$ SI Table 4), compared to single-phase exponential models. The only exception 
220 occurred when eDNA concentrations declined below detection so rapidly that no breakpoint was

221 observed (SI Table 4). In general, eDNA concentrations declined rapidly in all streams, with 80-

$22290 \%$ of the degradation occurring within the first day regardless of primer size (SI Figure 2).

223 After this point, degradation was followed by an abrupt change at the break-point $\mathrm{t}^{\prime}$, leading to a

224 longer, slower rate constant, and the break-point consistently occurred during the first 24 hours

225 (i.e., between 4 hrs-1 day) of sampling for all size fragments (SI Table 2).

227 Flow had little effect on rate constants, but increased potential eDNA transport distances

228 We had expected that water velocity would result in either differential settling of eDNA

229 particles (i.e., faster removal in Low treatment) or increased evidence of resuspension (i.e.,

230 slower removal in High treatment). However, the rate of primary degradation $\left(\mathrm{k}_{1}\right)$ by velocity

231 was unique for each primer length (697: High $<$ Low $<$ Intermediate, 455: Low $=$ Intermediate $<$

232 High, 97: High $<$ Low = Intermediate; Figure 1). In contrast to primary degradation, for the

233 secondary rate constant $\left(\mathrm{k}_{2}\right)$, we found no consistent pattern among velocity treatments. Using

234 linear models to compare the slopes of the decline in concentration over time, we observed that

235 velocity was a significant variable only in the model for the 455 bp fragment $(p<0.05)$,

236 moderately significant $(\mathrm{p}<0.10)$ for $697 \mathrm{bp}$, and non-significant for the $97 \mathrm{bp}$ fragment,

237 however the full models were not statistically significant for either the 697 or $97 \mathrm{bp}$ fragments.

238 When comparing a stepwise linear regression approach exploring predictors of the resulting

239 degradation parameter estimates (e.g., $\mathrm{k}_{1}$ ), velocity was only included in the final model for the

240697 bp fragments (SI Table 3), while chlorophyll a and benthic organic matter were stronger

241 predictors for the estimates for the degradation of the 455 and $97 \mathrm{bp}$ fragments. Consistent with

242 this observation but against our initial expectations, we found no statistical evidence of 
243 interaction between our biofilm and velocity treatments on eDNA degradation (LMM, $p>0.05$;

244 SI Table 3). Thus, we found no consistent influence of the velocity treatments on eDNA

245 degradation among primer sets (SI Table 3) suggesting an overriding influence of biology in

246 driving rates of degradation 5 .

247 While flow itself did not influence our observed rate constants in our experimental setup,

248 in the context of natural streams our results imply that water velocity has strong control on water

249 column eDNA concentrations as downstream flow advects and disperses eDNA downstream. If

250 continuous eDNA degradation and downstream transport is simultaneous, variation in water

251 velocity likely results in spatial separation of eDNA concentration at the same "state" of

252 degradation depending on the instream conditions. This spatial separation has strong implications

253 about the interpretation of water column eDNA concentrations, particularly in relation to

254 whether a species is presently nearby or some distance upstream. In this study, our velocity

255 treatment ranged from 0.1 to $0.8 \mathrm{~m} \mathrm{~s}^{-1}$, which represents only a small portion of the range in

256 environmental flows and water fluxes found in natural systems. For example, in an inter-biome

257 study, the mean velocity across 36 headwater streams ( $1^{\text {st }}$ to $3^{\text {rd }}$ order) ranged from nearly 0.01 to

$2580.93 \mathrm{~m} \mathrm{~s}^{-1}\left(\mathrm{Q}=2 \mathrm{~L} \mathrm{~s}^{-1} \text {, up to } 268 \mathrm{~L} \mathrm{~s}^{-1}\right)^{40}$, which presents a broad range of potential instream

259 velocities within a stream channel. Even within natural systems, the interaction between the

260 water column and the streambed creates variation in water velocities that are likely not captured

261 in these simplified recirculating streams.

Biofilm increased eDNA rate constants

264 In contrast to velocity (i.e., advection), biofilms had a stronger effect on degradation,

265 with faster rates found in streams with $>50 \%$ biofilm cover relative to bare or nearly bare 
266 substrate ( 0 and 25\%, respectively, Figure 1$)$. Across all biofilm and velocity treatments, we used

267 stepwise linear regressions to test for biological predictors of degradation estimates for $\mathrm{k}_{1}$ and $\mathrm{k}_{2}$.

268 For the $97 \mathrm{bp}$ fragment, $\mathrm{k}_{1}$ was best predicted by biofilm metrics (Full LM: $\left.\mathrm{R}^{2}=0.44, \mathrm{p}=0.04\right)$,

269 with biofilm chlorophyll $a(\mathrm{p}=0.013)$ and benthic OM $(\mathrm{p}=0.06)$ strongly predicting $\mathrm{k}_{1}$. Similar

270 effects were observed with the 455 bp fragments (Full LM: $\mathrm{R}^{2}=0.38, \mathrm{p}=0.08$; chlorophyll a $\mathrm{p}=$

$2710.006 ; \mathrm{OM} \mathrm{p}=0.067$ ), but as mentioned, velocity was the only significant predictor for the

272 estimates resulting from the $697 \mathrm{bp}$ fragments (Full LM: $\mathrm{R}^{2}=0.38, \mathrm{p}=0.08$; Velocity $\mathrm{p}=0.03$ ).

273 However, for all fragment lengths we found no significant predictors of $\mathrm{k}_{2}$ and $\mathrm{t}$ '.

274 The specifics of biofilm-mediated eDNA degradation remains unexplored to date, and in

275 our study, we cannot separate the relative role of the water column versus the benthic biofilms on

276 the persistence of water column eDNA. While there is evidence that stream water

277 physiochemical variables influence rate constants, such as temperature, $\mathrm{pH}$, and dissolved

278 organic carbon (DOC) in lakes ${ }^{19,20,41}$, these factors did not vary among the recirculating streams

279 used in this study (ANOVA $\mathrm{p}>0.05$ for all). While biofilm coverage increased microbial

280 colonization as measured via stream metabolism (Hanrahan et al. unpublished data), we did not

281 quantify microbial activity at the substrate scale (i.e., on individual rocks) and as such cannot tie

282 eDNA degradation directly to bacterial carbon demand. Moreover, a recent study suggested that

283 eDNA degradation was not strongly related to bacterial abundance ${ }^{41}$. It is possible that biofilm

284 architecture alone can act physically as a sorptive "sponge" for eDNA retention, resulting in

285 either temporary or permanent removal of particles from the water column ${ }^{30,42}$. Biofilm-

286 mediated retention increases the likelihood of subsequent microbial processing, but the fate of

287 biofilm-trapped eDNA certainly deserves further study, including how different eDNA source

288 material (e.g., urine vs. cells vs. tissue fragments) might be uniquely degraded. 
Primer length influenced eDNA rate constants and detectability

Overall, we anticipated that shorter fragments would degrade slower than larger

292 fragments. Our initial rate constant coefficients, $\mathrm{k}_{1}$, ranged from 8-35 day ${ }^{-1}$ for the $697 \mathrm{bp}$

293 fragment, 8-32 day $^{-1}$ for the $455 \mathrm{bp}$ fragment, and 5-12 day $^{-1}$ for the $97 \mathrm{bp}$ fragment (Figure 1).

294 Our results were consistent with the findings of a previous study ${ }^{34}$ where that eDNA fragment

295 length was related to detectability over time. Depending on eDNA fragment length, slopes

296 describing the shorter fragments $(97 \mathrm{bp})$ were different from longer (455 and $697 \mathrm{bp})$ fragments

297 based on all pooled eDNA concentration data (LM with interaction term fragment*time, $\mathrm{p}<$

298 0.05). Our study was the first to address how the combination of biofilm, velocity, and fragment

299 length would alter instream eDNA concentration, it is clear that we have merely scratched the

300 surface of the potential for the application of assays that target varying fragments. While more

301 testing is needed to determine any detection "thresholds" among different fragment sizes, our

302 primer that targeted smaller bp fragment resulted in eDNA degradation rate constants that were

303 half the rate constant for the longer fragment. Importantly, observed variation in eDNA

304 degradation rate constants as a result of target eDNA fragment length imposes a significant

305 methodological challenge for interpreting eDNA results and assay design.

306 Despite the challenge posed, the application of assays similar to those described in this

307 paper may provide a potential opportunity for improved interpretation of positive eDNA

308 detection under natural conditions. Broadly, the result of our nested primer approach suggests

309 that incorporating such analytical techniques into eDNA approaches may allow more

310 information to be gained from a single sample than a single relative eDNA concentration alone.

311 For example, our study was consistent with the results presented by Jo et al. ${ }^{34}$ where detection of 
312 a longer eDNA fragment is correlated with recent species presence, and therefore the relationship

313 between long and short fragments can potentially indicate species recency or eDNA processing.

314 Though the application of this technique demands further study and validation, the choice of

315 primers that amplify different sized eDNA fragments could be optimized to support a variety of

316 experimental approaches or even applied in the context of management goals. For example, if the

317 goal is rapid detection of species and the assay efficiencies are comparable, a larger fragment

318 size might yield contemporaneous results, while a smaller fragment size could be used for more

319 general presence and absence surveys. When larger and smaller fragment assays are combined,

320 the nested primer approach could indicate an eDNA "processing continuum" over time (and

321 space in flowing waters), because the concentration of the smaller fragment relative to the larger

322 fragment should begin to dominate as degradation proceeds. If successful, the use of nested

323 primers could be effective in informing the when a target species was present, especially in

324 flowing waters where inference is confounded as a result of simultaneous transport and

325 degradation.

326 We do note that this method certainly demands further optimization and testing to

327 determine its reliability and ultimate potential. Currently, the body of literature that describes the 328 application of different fragment sizes on eDNA detection is limited, and results of these studies

329 have been mixed. In one study, the authors observed that longer eDNA fragments degrade faster 330 than shorter fragments in mesocosms ${ }^{34}$. In another, also using a "nested" design in fish tanks,

331 workers found that the rate of decay was not dependent on fragment length but rather its origin

332 (e.g., nuclear vs. mitochondrial) ${ }^{33}$. We would also like to recognize that while in need of further

333 study, the application of dual assays that reliably amplify different target lengths could serve as 
334 an additional validation check for eDNA analyses, potentially lending insight on detecting type I

335 and II errors for environmental samples.

337 The importance of degradation rate reporting and modelling

338 Our results also underscore the importance of reporting eDNA degradation rates under

339 both monophasic and biphasic conditions, so that a more complete picture of eDNA degradation

340 can be drawn. Under all of our experimental conditions, our initial rate constant for the biphasic

341 model, $\mathrm{k}_{1}$, for eDNA was much higher than previously observed rate constants for mesocosm

342 experiments that reported monophasic decay $\left(k=0.05-17.9\right.$ day $\left.^{-1}\right)$ and for our estimates of

343 monophasic degradation using data from this study $\left(k=0.36-2.6\right.$ day $\left.^{-1}\right)$ (Figure 2), though this

344 observation represents an inherent assumption of the biphasic model. While monophasic

345 degradation does capture the decline in eDNA concentration over time, we argue that the

346 significance of the two-phase degradation model is that it more accurately represents the initial

347 rapid decline in concentration that ultimately alters the available eDNA for capture and

348 detection.

349 To this end, we illustrate the importance of interpreting eDNA degradation rates under

350 varying conditions using a simple modeling scenario. To determine how long eDNA remains

351 detectable in the water column, we used the decay curves predicted by a single-phase decay

352 model to reflect how far eDNA might travel in time and over stream distance. These simple

353 models reflect our measured degradation constants under different conditions and thus illustrate

354 the impact of both biofilm and velocity for altering predicted eDNA instream concentrations.

355 For example, after 8 hours the $97 \mathrm{bp}$ fragment degradation curves are distinct: the modeled water

356 column eDNA concentration High velocity - 100\% biofilm and Low velocity - 0\% biofilm 
357 models differed by 7 times, with "sampled" concentrations of $\sim 4000$ copies $\mathrm{mL}^{-1}$ vs. $\sim 27,000$ 358 copies $\mathrm{mL}^{-1}$, respectively (Figure 3 ). If these decay rates per unit time were converted to a per 359 unit distance, we see a 10x difference over space after only $8 \mathrm{hr}$ simply due to differences in

360 flow (Figure 3). These effects were even more pronounced using the longer primer length (697

$361 \mathrm{bp}$ ), where eDNA became undetectable after $\sim 6 \mathrm{hrs,} \mathrm{and} \sim 2-10$ kilometers downstream. In every

362 scenario, even with a low velocity and high rate constant (Low $-100 \%$ biofilm), water column 363 eDNA remained detectable for long distances in high flows (e.g., up to $8 \mathrm{~km}$ ) before becoming 364 undetectable in the water column.

366 Context-dependency of eDNA degradation is a challenge for the use of eDNA in flowing

367 environments

368 Untangling the physical and biological factors influencing eDNA degradation and

369 removal from the water column will improve predictive power and interpretation of eDNA

370 detection results for the presence of critical species in streams and rivers. While the future of

371 eDNA technology remains bright, the leap to estimating species location and abundance in

372 flowing waters remains challenging. Our results suggest that the interaction between biofilm

373 cover and water velocity may further confound attempts to infer target species abundance or

374 location using eDNA approaches. Not only can eDNA be transported long distances in streams

375 and rivers with high water velocities, but eDNA also degrades while in transport, either via water

376 column or benthic process, or the interaction of the two. As such, eDNA detection and

377 persistence depends strongly on environmental context (Figure 1). Moreover, the importance of

378 physical and spatial variability of biofilms, and their effect on eDNA degradation and removal,

379 remains largely unexplored. In the simplified recirculating streams used in this study, the 
380 presence of benthic biofilm strongly influenced the degradation of eDNA; however, biofilms in

381 natural systems are spatially and temporally heterogeneous ${ }^{29,43}$, and thus their role in the context

382 of eDNA detection in the field deserves further exploration.

383

384 Acknowledgements

385 We thank S. Lee, E. Richmond, A. Reisinger for assistance. We are grateful to the NY DEC for

386 allowing us to use water from their ponds. This is a publication of the University of Notre

387 Dame's Environmental Change Initiative.

388

389 Supplemental Information

390 Detailed methods for eDNA quantification, and figures and tables reporting rate constants can be 391 found in the Supplemental Information.

392

$393 \quad$ Funding statement

394 This publication was partially developed under AJS's Science To Achieve Results (STAR)

395 Fellowship Assistance Agreement no. FP-91781601-0 awarded by the U.S. Environmental

396 Protection Agency (EPA). It has not been formally reviewed by the EPA. SPE, ER, JLT, and DB

397 were supported by USDA Grant 2013-33522-21007.

398

$399 \quad \underline{\text { Ethics }}$

400 We declare no ethical considerations.

401

402 Competing interests 
403 We have no competing interests.

404

405 Author contributions

406 All coauthors equally contributed to the conception and design of the experiment, acquired the 407 data, interpreted and analyzed the data, drafted and revised the manuscript, and gave approval of 408 the manuscript for publication.

409

410 


\section{References:}

412 (1) Rees, H. C.; Maddison, B. C.; Middleditch, D. J.; Patmore, J. R. M.; Gough, K. C. REVIEW The Detection of Aquatic Animal Species Using Environmental DNA - a Review of EDNA as a Survey Tool in Ecology. J. Appl. Ecol. 2014, 51 (5), 1450-1459.

(3) Trebitz, A. S.; Hoffman, J. C.; Darling, J. A.; Pilgrim, E. M.; Kelly, J. R.; Brown, E. A.; Lodge, D. M.; Turner, C. R.; Jerde, C. L.; Barnes, M. a; Chadderton, L.; Egan, S. P.; Feder, J. L.; Mahon, A. R.; Pfrender, M. E. Conservation in a Cup of Water: Estimating Biodiversity and Population Abundance from Environmental DNA. Mol. Ecol. 2012, 21 (11), 2555-2558. Chadderton, W. L.; Egan, S. P.; Grey, E. K.; Hashsham, S. A.; Klymus, K. E.; Mahon, A. R.; Ram, J. L.; Schultz, M. T.; Spepien, C. A.; Schardt, J. C. Early Detection Monitoring for Aquatic Non-Indigenous Species: Optimizing Surveillance, Incorporating Advanced Technologies, and Identifying Research Needs. J. Environ. Manage. 2017, 202, 299-310.

(4) Ficetola, G. F.; Miaud, C.; Pompanon, F.; Taberlet, P. Species Detection Using Environmental DNA from Water Samples. Biol. Lett. 2008, 4 (4), 423-425.

(5) Barnes, M. A.; Turner, C. R.; Jerde, C. L.; Renshaw, M. A.; Chadderton, W. L.; Lodge, D. M. Environmental Conditions Influence EDNA Persistence in Aquatic Systems. Environ. Sci. Technol. 2014, 48 (3), 1819-1827.

(6) Thomsen, P. F.; Kielgast, J.; Iversen, L. L.; Wiuf, C.; Rasmussen, M.; Gilbert, M. T. P.; Orlando, L.; Willerslev, E. Monitoring Endangered Freshwater Biodiversity Using Environmental DNA. Mol. Ecol. 2012, 21 (11), 2565-2573.

(7) Jerde, C. L.; Mahon, A. R.; Chadderton, W. L.; Lodge, D. M. "Sight-Unseen” Detection of Rare Aquatic Species Using Environmental DNA. Conserv. Lett. 2011, 4 (2), 150-157.

(8) Bohmann, K.; Evans, A.; Gilbert, M. T. P.; Carvalho, G. R.; Creer, S.; Knapp, M.; Yu, D. W.; de Bruyn, M. Environmental DNA for Wildlife Biology and Biodiversity Monitoring. Trends Ecol. Evol. 2014, 29 (6), 358-367.

(9) Kelly, R. P.; Port, J. a.; Yamahara, K. M.; Martone, R. G.; Lowell, N.; Thomsen, P. F.; Mach, M. E.; Bennett, M.; Prahler, E.; Caldwell, M. R.; Crowder, L. B. Harnessing DNA to Improve Environmental Management. Science Policy Forum. 2014, 344 (6191). 1455 1456.

(10) Egan, S. P.; Grey, E.; Olds, B.; Feder, J. L.; Ruggiero, S. T.; Tanner, C. E.; Lodge, D. M. Rapid Molecular Detection of Invasive Species in Ballast and Harbor Water by Integrating Environmental DNA and Light Transmission Spectroscopy. Environ. Sci. Technol. 2015, 49 (7): 4113-4121.

(11) Egan, S. P.; Barnes, M. A.; Hwang, C.-T.; Mahon, A. R.; Feder, J. L.; Ruggiero, S. T.; Tanner, C. E.; Lodge, D. M. Rapid Invasive Species Detection by Combining Environmental DNA with Light Transmission Spectroscopy. Conserv. Lett. 2013, 6 (6), 402-409.

(12) Deiner, K.; Walser, J.-C.; Mächler, E.; Altermatt, F. Choice of Capture and Extraction Methods Affect Detection of Freshwater Biodiversity from Environmental DNA. Biol. Conserv. 2015, 183, 53-63.

(13) Darling, J. a; Mahon, A. R. From Molecules to Management: Adopting DNA-Based Methods for Monitoring Biological Invasions in Aquatic Environments. Environ. Res. 2011, 111 (7), 978-988.

(14) Simmons, M.; Tucker, A.; Chadderton, W. L.; Jerde, C. L.; Mahon, A. R. Active and Passive Environmental DNA Surveillance of Aquatic Invasive Species. Can. J. Fish. 
Aquat. Sci. 2015, 73 (1), 76-83.

(15) Wilcox, T. M.; McKelvey, K. S.; Young, M. K.; Jane, S. F.; Lowe, W. H.; Whiteley, A. R.; Schwartz, M. K. Robust Detection of Rare Species Using Environmental DNA: The Importance of Primer Specificity. PLoS One 2013, 8 (3), e59520.

(16) Ficetola, G. F.; Pansu, J.; Bonin, A.; Coissac, E.; Giguet-Covex, C.; De Barba, M.; Gielly, L.; Lopes, C. M.; Boyer, F.; Pompanon, F.; Raye, G.; Taberlet, P. Replication Levels, False Presences and the Estimation of the Presence/Absence from EDNA Metabarcoding Data. Mol. Ecol. Resour. 2015, 15 (3), 543-556.

(17) Schmidt, B. R.; Kerry, M.; Ursenbacher, S.; Hyman, O. J.; Collins, J. P.; Kery, M.; Ursenbacher, S.; Hyman, O. J.; Collins, J. P. Site Occupancymodels in the Analysis of Environmental DNA Presence/Absence Surveys: A Case Study of an Emerging Amphibian Pathogen. Methods Ecol. Evol. 2013, 4 (7), 646-653.

(18) Shogren, A. J.; Tank, J. L.; Andruszkiewicz, E.; Olds, B.; Mahon, A. R.; Jerde, C. L.; Bolster, D. Controls on EDNA Movement in Streams: Transport, Retention, and Resuspension. Sci. Rep. 2017, 7 (1), 5065.

(19) Eichmiller, J. J.; Best, S. E. S. E.; Sorensen, P. W. Effects of Temperature and Trophic State on Degradation of Environmental DNA in Lake Water. Environ. Sci. Technol. 2016, 50 (4), 1859-1867.

(20) Strickler, K. M.; Fremier, A. K.; Goldberg, C. S. Quantifying Effects of UV-B, Temperature, and PH on EDNA Degradation in Aquatic Microcosms. Biol. Conserv. 2015, 183, 85-92.

(21) Jane, S. F.; Wilcox, T. M.; Mckelvey, K. S.; Young, M. K.; Schwartz, M. K.; Lowe, W. H.; Letcher, B. H.; Whiteley, A. R. Distance, Flow and PCR Inhibition: EDNA Dynamics in Two Headwater Streams. Mol. Ecol. Resour. 2015, 15 (1), 216-227.

(22) Pilliod, D. S.; Goldberg, C. S.; Arkle, R. S.; Waits, L. P. Estimating Occupancy and Abundance of Stream Amphibians Using Environmental DNA from Filtered Water Samples. Can. J. Fish. Aquat. Sci. 2013, 70 (8), 1123-1130.

(23) Wilcox, T. M.; McKelvey, K. S.; Young, M. K.; Sepulveda, A. J.; Shepard, B. B.; Jane, S. F.; Whiteley, A. R.; Lowe, W. H.; Schwartz, M. K. Understanding Environmental DNA Detection Probabilities: A Case Study Using a Stream-Dwelling Char Salvelinus Fontinalis. Biol. Conserv. 2016, 194, 209-216.

(24) Sansom, B. J.; Sassoubre, L. M. Environmental DNA (EDNA) Shedding and Decay Rates to Model Freshwater Mussel EDNA Transport in a River. Environ. Sci. Technol. 2017, 51 (24), 14244-14253, acs.est.7b05199.

(25) Klymus, K. E.; Richter, C. A.; Chapman, D. C.; Paukert, C. Quantification of EDNA Shedding Rates from Invasive Bighead Carp Hypophthalmichthys Nobilis and Silver Carp Hypophthalmichthys Molitrix. Biol. Conserv. 2015, 183, 77-84.

(26) Sassoubre, L. M.; Yamahara, K. M.; Gardner, L. D.; Block, B. A.; Boehm, A. B. Quantification of Environmental DNA (EDNA) Shedding and Decay Rates for Three Marine Fish. Environ. Sci. Technol. 2016, 50 (19), 10456-10464.

(27) Dejean, T.; Valentini, A.; Duparc, A.; Pellier-Cuit, S.; Pompanon, F.; Taberlet, P.; Miaud, C. Persistence of Environmental DNA in Freshwater Ecosystems. PLoS One 2011, 6 (8), e23398.

(28) Battin, T. J.; Kaplan, L. A.; Denis Newbold, J.; Hansen, C. M. E. Contributions of Microbial Biofilms to Ecosystem Processes in Stream Mesocosms. Nature 2003, 426, $439-442$. 
(29) Battin, T. J.; Besemer, K.; Bengtsson, M. M.; Romani, A. M.; Packmann, A. I. The Ecology and Biogeochemistry of Stream Biofilms. Nat. Rev. Microbiol. 2016, 14, 251263.

(30) Shogren, A. J.; Tank, J. L.; Andruszkiewicz, E. A.; Olds, B.; Jerde, C.; Bolster, D. Modelling the Transport of Environmental DNA through a Porous Substrate Using Continuous Flow-through Column Experiments. J. R. Soc. Interface 2016, 13 (119), 20160290.

(31) Aubeneau, A. F.; Drummond, J. D.; Schumer, R.; Bolster, D.; Tank, J. L.; Packman, A. I. Effects of Benthic and Hyporheic Reactive Transport on Breakthrough Curves. Freshw. Sci. 2015, 34 (1), 301-315.

(32) Aubeneau, A. F.; Hanrahan, B.; Bolster, D.; Tank, J. Biofilm Growth in Gravel Bed Streams Controls Solute Residence Time Distributions. J. Geophys. Res. Biogeosciences 2016, 121 (7), 1840-1850.

(33) Bylemans, J.; Furlan, E. M.; Gleeson, D. M.; Hardy, C. M.; Duncan, R. P. Does Size Matter? An Experimental Evaluation of the Relative Abundance and Decay Rates of Aquatic Environmental DNA. Environ. Sci. Technol. 2018, 52 (11), 6408-6416.

(34) Jo, T.; Murakami, H.; Masuda, R.; Sakata, M. K.; Yamamoto, S.; Minamoto, T. Rapid Degradation of Longer DNA Fragments Enables the Improved Estimation of Distribution and Biomass Using Environmental DNA. Mol. Ecol. Resour. 2017, 17 (6), e25-e33.

(35) Eichmiller, J. J.; Miller, L. M.; Sorensen, P. W. Optimizing Techniques to Capture and Extract Environmental DNA for Detection and Quantification of Fish. Mol. Ecol. Resour. 2016, $16(1), 56-68$.

(36) Muggeo, V. M. . Estimating Regression Models with Unknown Break Points. Stat. Med. 2003, 22, 3055-3071.

(37) Muggeo, V. M. . Segmented: An R Package to Fit Regression Models with Broken-Line Relationships. $R$ Documentation. 2008, pp 20-25.

(38) Bates, D.; Machler, M.; Bolker, B.; Walker, S. Fitting Linear Mixed-Effects Models Using Lme4. R Doc. 2014.

(39) Bylemans, J.; Furlan, E. M.; Pearce, L.; Daly, T.; Gleeson, D. M. Improving the Containment of a Freshwater Invader Using Environmental DNA (EDNA) Based Monitoring. Biol. Invasions 2016, 18 (10), 3081-3089.

(40) Johnson, L. T.; Tank, J. L.; Hall Robert O., J.; Mulholland, P. J.; Hamilton, S. K.; Valett, H. M.; Webster, J. R.; Bernot, M. J.; McDowell, W. H.; Peterson, B. J.; Thomas, S. M. Quantifying the Production of Dissolved Organic Nitrogen in Headwater Streams Using 15N Tracer Additions. Limnol. Oceanogr. 2013, 58 (4), 1271-1285.

(41) Tsuji, S.; Ushio, M.; Sakurai, S.; Minamoto, T.; Yamanaka, H. Water TemperatureDependent Degradation of Environmental DNA and Its Relation to Bacterial Abundance. 2017, 12 (4), e0176608.

(42) Turner, C. R.; Uy, K. L.; Everhart, R. C. Fish Environmental DNA Is More Concentrated in Aquatic Sediments than Surface Water. Biol. Conserv. 2014, 183, 93-102.

(43) Battin, T. J.; Kaplan, L. A.; Findlay, S.; Hopkinson, C. S.; Marti, E.; Packman, A. I.; Newbold, J. D.; Sabater, F. Biophysical Controls on Organic Carbon Fluxes in Fluvial Networks. Nat. Geosci 2008, 1 (2), 95-100. 


\section{$\underline{\text { Figures }}$}
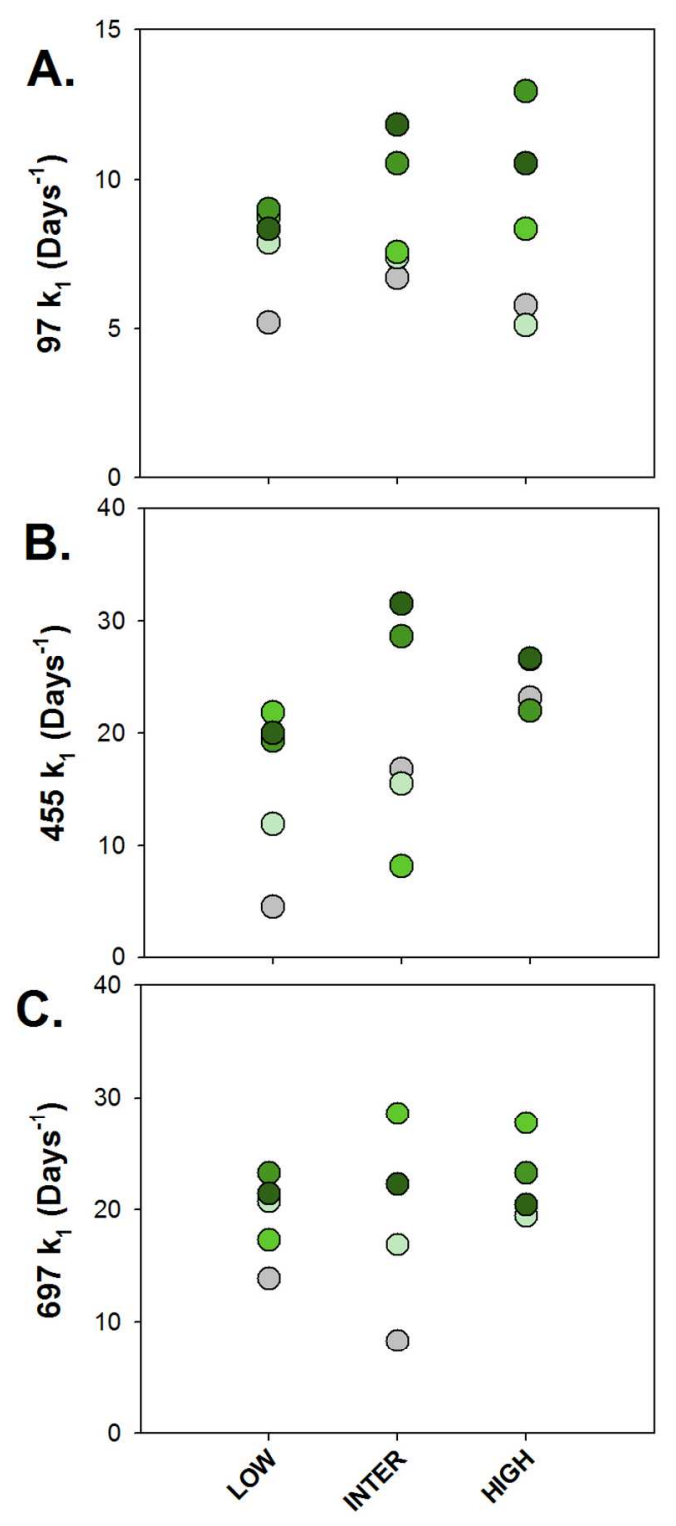

Flow Treatment

Figure 1: Estimated primary $\left(\mathrm{k}_{1}\right)$ degradation terms from biphasic model fitting for: A) $97 \mathrm{bp}, \mathrm{B}$ ) $455 \mathrm{bp}$, and C) $697 \mathrm{bp}$ eDNA fragments across all velocity treatments (x-axis). Color gradient of dots represents biofilm cover treatment, from gray $(0 \%)$ to dark green (100\%). Secondary degradation terms are reported in SI Table 2. 


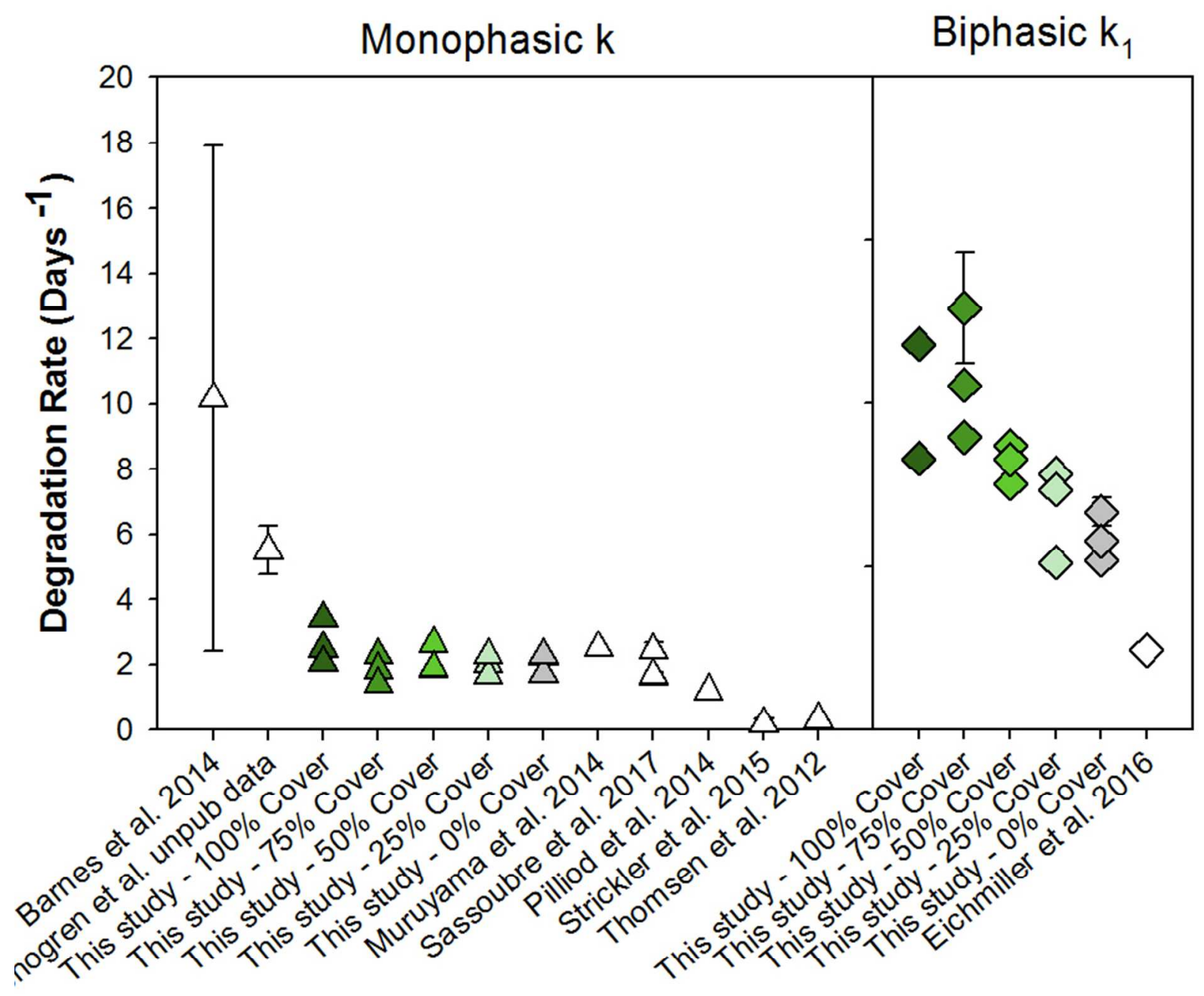

Figure 2: Meta-analysis of previously published studies on fish eDNA rate constant coefficients (white) and this study (gray to green gradient) for monophasic (triangles) and biphasic (diamond) rate constants ( $\mathrm{k} \mathrm{vs}_{1}$ ). Rate constants expressed in days ${ }^{-1}$ ( $\pm \mathrm{SE}$ if reported). 

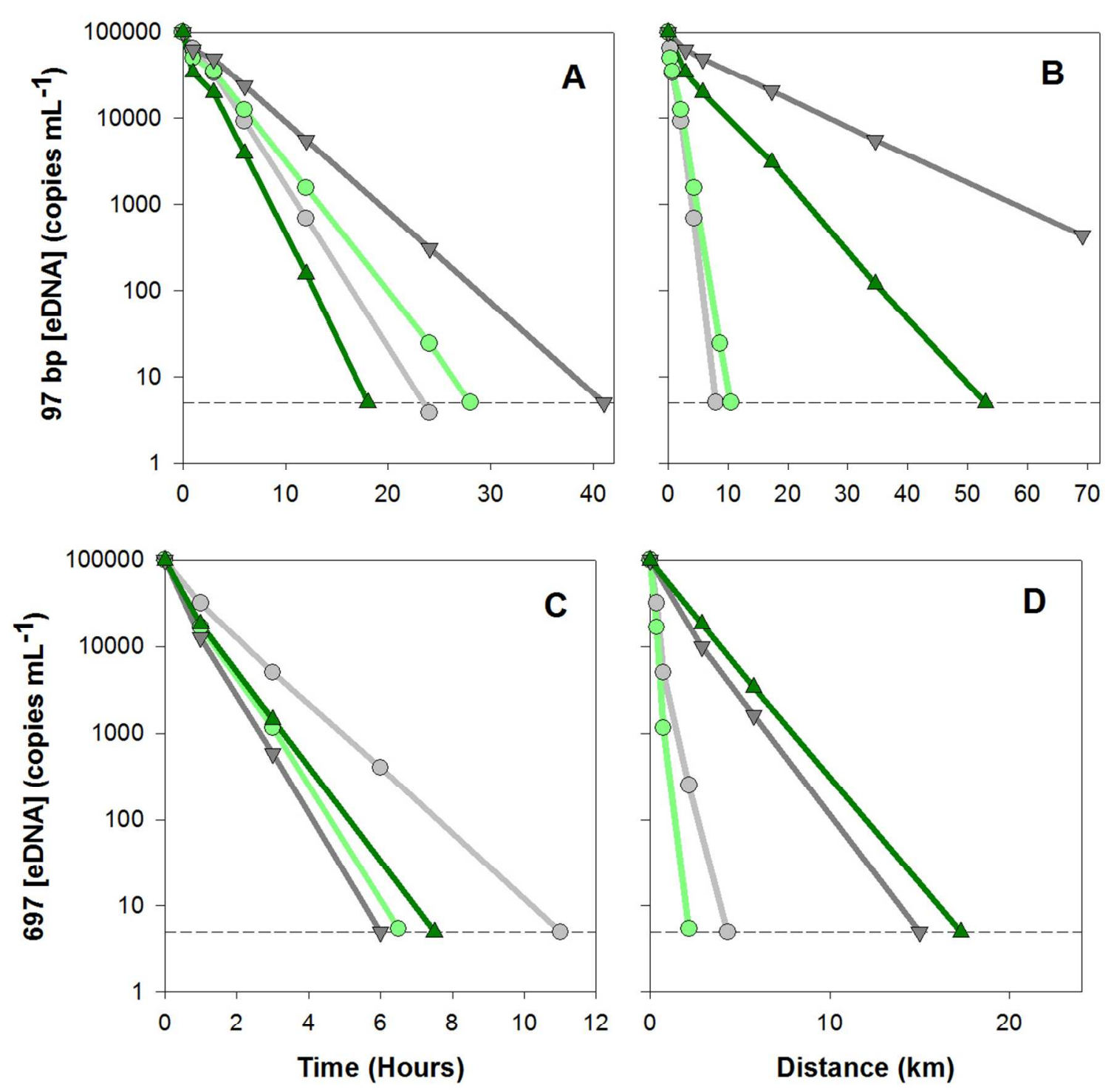

- - - Low - 0\% biofilm

- Low $-100 \%$ biofilm

$\rightarrow$ High - 0\% biofilm

$\rightarrow$ High $-100 \%$ biofilm

---- qPCR Limit of Quantification

Figure 3: Projected (i.e., modeled) eDNA concentration in time (A: 97 bp fragment, C: 697 bp fragment) and distance (B: 97 bp fragment, D: $697 \mathrm{bp}$ fragment) based on 4 flow/biofilm scenarios (Low-0\%, Low-100\%, High- $0 \%$, and High-100\% biofilm coverage) using the estimated $\mathrm{k}_{1}$ term from the artificial stream experiment. 

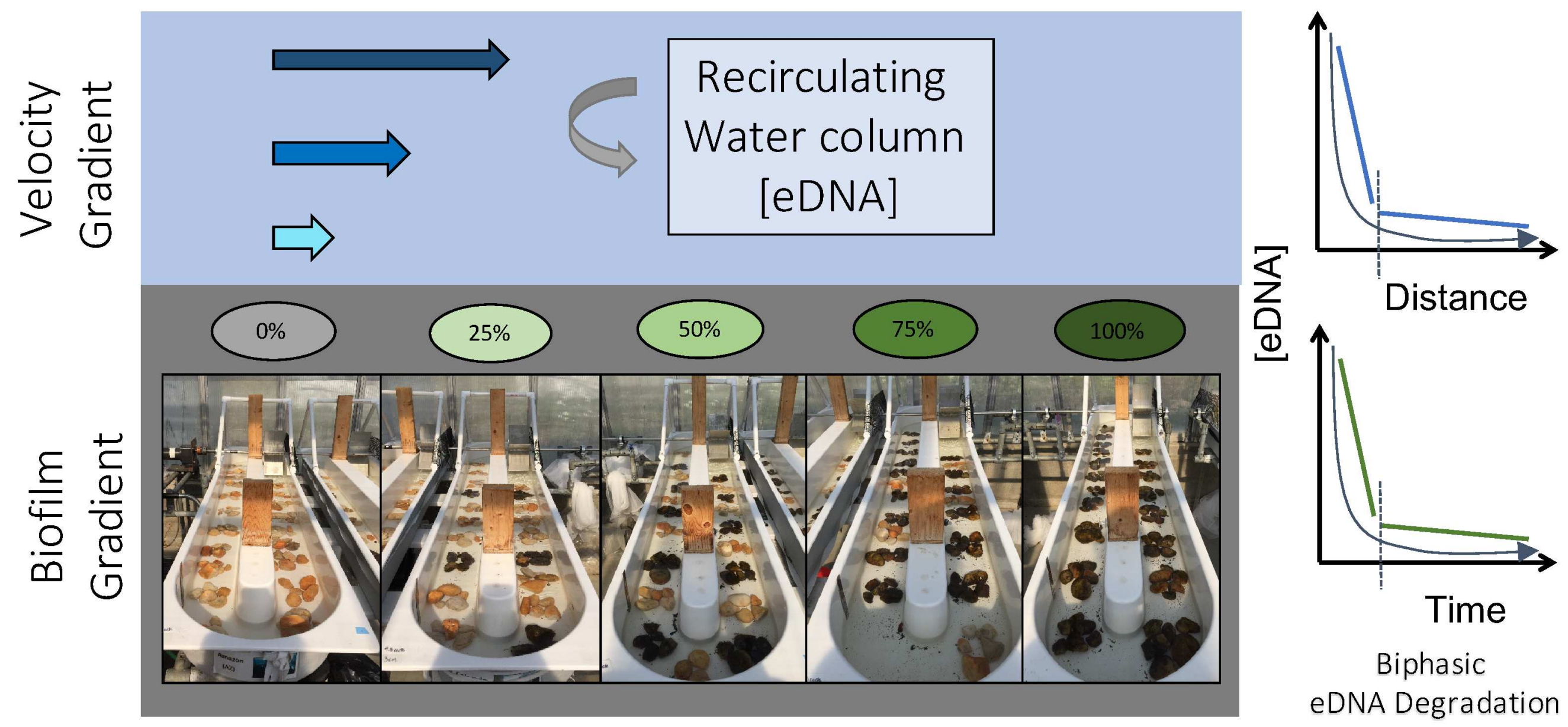
Page 29 of 30

Moñvironmental Science \& Technology

Biphasic $k_{1}$

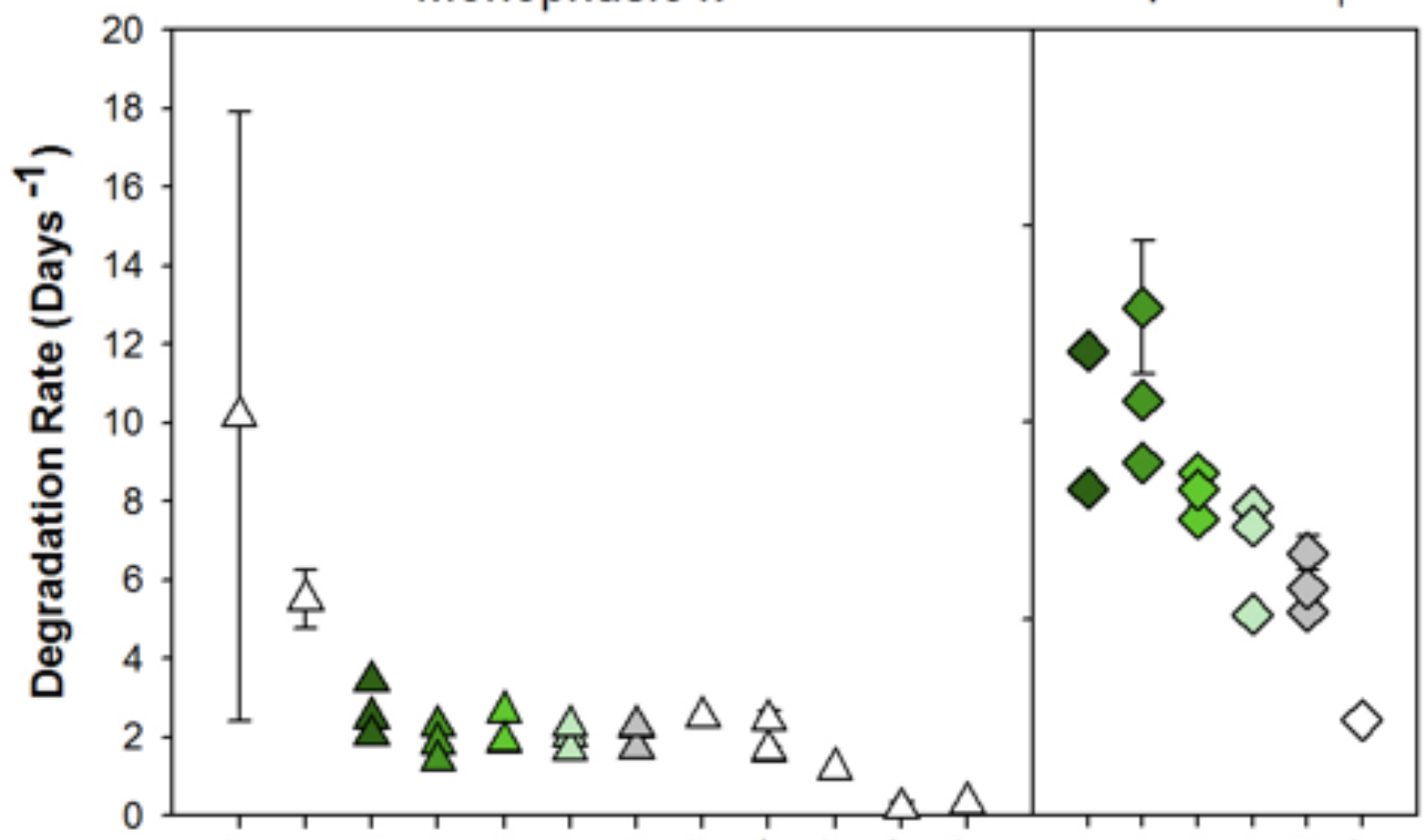

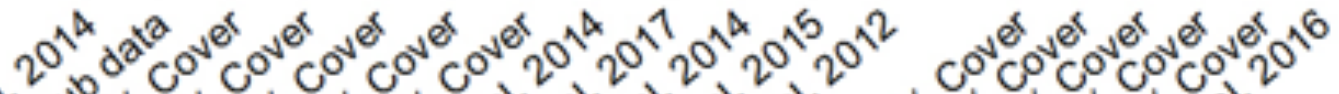

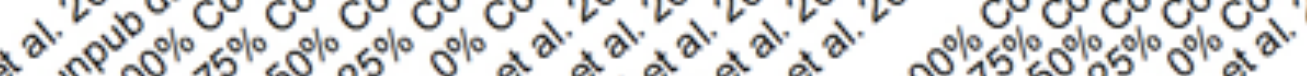

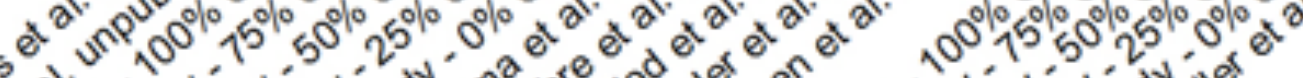

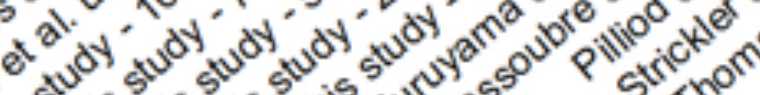




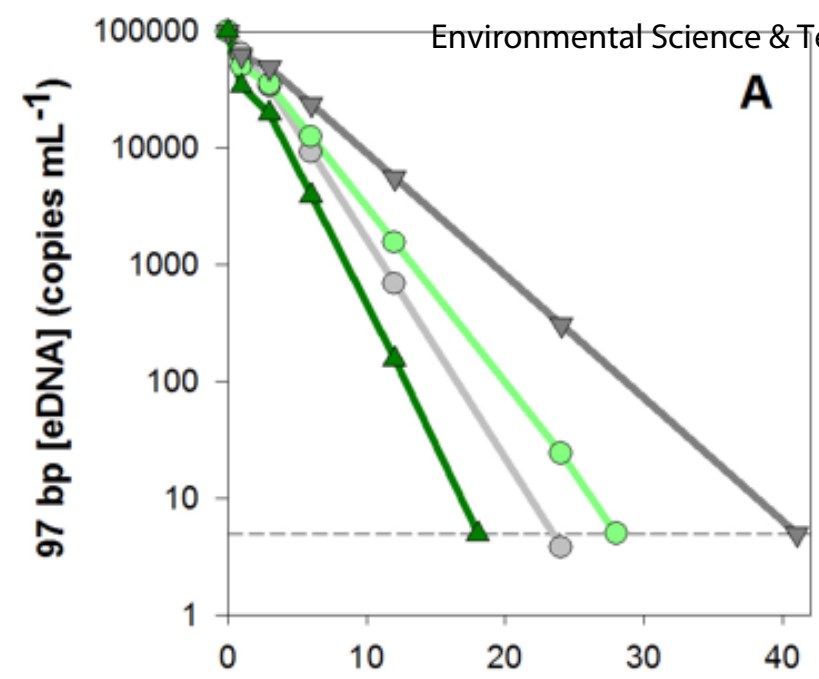

Page 30 of 30
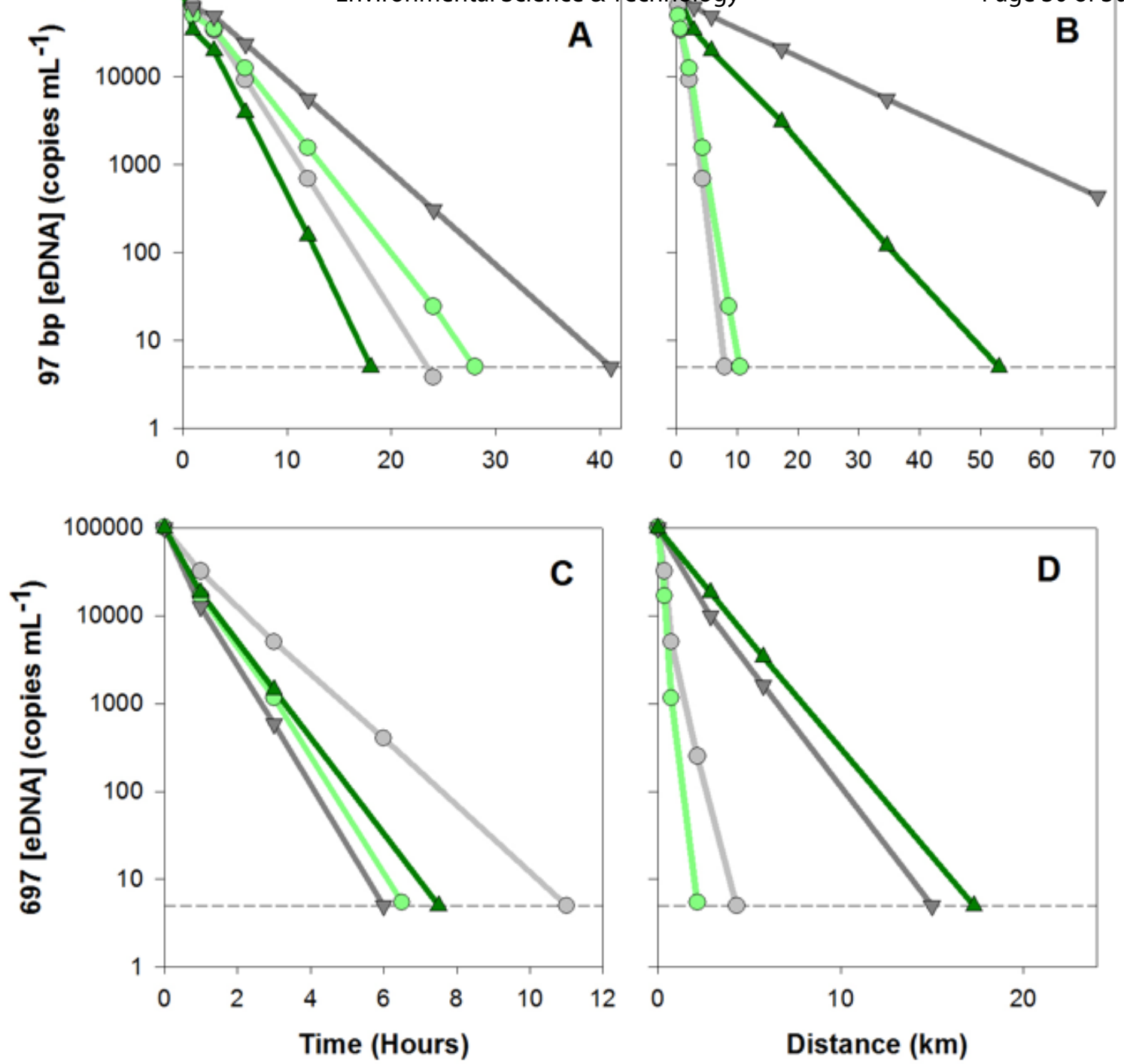

- - Low - 0\% biofilm

- Low - $100 \%$ biofilm

ACS ParagonPluF Figh vire\%

- High - $100 \%$ biofilm

---- QPCR Limit of Quantification 